\title{
Hypermethylation in the ZBTB20 gene is associated with major depressive disorder
}

\author{
Matthew N Davies ${ }^{1 *}$, Lutz Krause ${ }^{2 \dagger}$, Jordana T Bell ${ }^{1 \dagger}$, Fei Gao ${ }^{3}$, Kirsten J Ward ${ }^{1}$, Honglong Wu ${ }^{3}$, Hanlin $\mathrm{Lu}^{3}$, \\ Yuan Liu ${ }^{3}$, Pei-Chein Tsai ${ }^{1}$, David A Collier ${ }^{4}$, Therese Murphy ${ }^{5}$, Emma Dempster ${ }^{5}$, Jonathan Mill ${ }^{4,5}$, \\ UK Brain Expression Consortium, Alexis Battle? , Sara Mostafavi', Xiaowei Zhu', Anjali Henders², \\ Enda Byrne ${ }^{2,6}$, Naomi R Wray ${ }^{2,6}$, Nicholas G Martin ${ }^{2 \dagger}$, Tim D Spector ${ }^{1 \dagger}$ and Jun Wang ${ }^{3+}$
}

\begin{abstract}
Background: Although genetic variation is believed to contribute to an individual's susceptibility to major depressive disorder, genome-wide association studies have not yet identified associations that could explain the full etiology of the disease. Epigenetics is increasingly believed to play a major role in the development of common clinical phenotypes, including major depressive disorder.

Results: Genome-wide MeDIP-Sequencing was carried out on a total of 50 monozygotic twin pairs from the UK and Australia that are discordant for depression. We show that major depressive disorder is associated with significant hypermethylation within the coding region of ZBTB20, and is replicated in an independent cohort of 356 unrelated case-control individuals. The twins with major depressive disorder also show increased global variation in methylation in comparison with their unaffected co-twins. ZBTB20 plays an essential role in the specification of the Cornu Ammonis-1 field identity in the developing hippocampus, a region previously implicated in the development of major depressive disorder.
\end{abstract}

Conclusions: Our results suggest that aberrant methylation profiles affecting the hippocampus are associated with major depressive disorder and show the potential of the epigenetic twin model in neuro-psychiatric disease.

\section{Background}

During development, dynamic changes to the epigenome play a critical role in establishing and maintaining each tissue within the body [1,2]. In particular, DNA methylation has been shown to play a critical role in the development of sub-regions of the brain. Epigenetic processes control several neurobiological and cognitive processes, including neurogenesis, the limbic system, neuronal activity, learning and memory, drug addiction, neurodegeneration and circadian rhythm [3]. Mutations in the methyl $\mathrm{CpG}$ binding protein 2 gene (MECP2) have been shown to lead to neurodevelopmental deficits, such as those associated with Rett syndrome [4], and aberrant DNA methylation signatures have been observed in

\footnotetext{
* Correspondence: matthew.1.davies@kcl.ac.uk

${ }^{\dagger}$ Equal contributors

'Department of Twin Research \& Genetic Epidemiology, King's College London, St Thomas' Hospital Campus, Westminster Bridge Road, London SE1 7EH, UK

Full list of author information is available at the end of the article
}

several neuropsychiatric disorders, including schizophrenia and bipolar disorder [5]. There is considerable interest, therefore, in investigating the role of epigenetics in the development of other psychiatric diseases, such as major depressive disorder (MDD) [3,6-10].

Although genetic variation and environmental stressors are believed to increase an individual's susceptibility to MDD, genome-wide association studies have not yet identified any replicated associations with depression that could explain the full etiology of the disease [3,11]. Twin studies of MDD have estimated its heritability to be approximately $37 \%$ [12], but may be higher for recurrent and early onset MDD [13]. However, the majority of monozygotic twin (MZT) pairs are discordant for MDD (only 20\% of male and 38\% of female MZT pairs show concordance for the disorder under the DSM-IV criteria [14]).

Several lines of evidence suggest a role for epigenetic factors in the development of depression. The delayed onset of the condition along with its episodic nature strongly suggests that it may have an epigenetic component [3]. 
Several studies of animal models for depression indicate that epigenetic processes may play an essential role in the pathology of the disease. In particular, several mice studies showed that the antidepressants imipramine, tranylcypromine and fluoxetine were able to induce epigenetic changes [15]. A human study comparing 39 unrelated, postmortem frontal cortex MDD samples to 26 controls [16] identified several differentially methylated regions enriched for neuronal growth and developmental genes, although these failed to replicate. Uddin et al. [17] compared blood methylation profiles of 33 subjects with a lifetime history of depression and 67 non-depressed adults using the $27 \mathrm{k}$ array and demonstrated that genome-wide methylation profiles distinguish between depressed and non-depressed individuals. It has been suggested that childhood adversities could increase depression risk via epigenetic mechanisms [6,18-22]. There is also increasing evidence to suggest that epigenetic variation between MZT pairs may play a key role in the etiology of psychopathology and contribute to phenotypic disconcordance [23].

In this study we used methylated DNA immunoprecipitation combined with ultra-deep sequencing (MeDIP-seq) to provide comprehensive coverage of the methylomic landscape in order to compare blood samples between MZT pairs discordant for MDD in two independent datasets (Figure 1). The first cohort (UK) comprised 27 discordant twin pairs from the UK while the second cohort (Australia) comprised 23 discordant pairs from Australia. Discordant MZT pairs constitute a powerful design for epigenetic studies, as the genomic DNA sequence is identical within twin pairs and SNPs and other DNA sequence variations are not confounding factors. Additionally, twin pairs are generally exposed to similar environmental influences and important age and cohort effects are controlled within the paired comparison.

\section{Results and discussion}

The regression analysis of the 27 UK discordant MZT pairs alone did not clearly identify any differentially methylated region (DMR) of genome-wide significance (using a conservative significance level of $9 \times 10^{-10}$; Table S1 in Additional file 1). However, several of the most differentially methylated genes were related to the pathology of MDD, namely CADPS1, PTPRM and ZBTB2O (zinc finger and BTB domain containing 20 gene). Similarly, the regression analysis of 23 Australian discordant MZT pairs did not identify any DMR of genome-wide significance (Table S4 in Additional file 1). The second most differentially methylated gene (EPHB1), however, was related to the etiology of MDD (Additional file 1). The meta-analysis of both UK and Australian datasets identified 17 DMRs of genomewide significance $(P<0.05$, Bonferoni adjusted for approximately $11 \mathrm{M}$ tests; Table 1; Figure 2). Four of these 17
DMRs were located within genes related to the pathology of MDD, namely ZBTB20, AGTPBP1, TBC1D8 and CLSTN1, and selected for replication. The region was replicated in an independent replication cohort of 354 unrelated, age-matched females and showed an increased methylation of $28.2 \%$ in the 118 MDD cases compared to the 236 controls $(P=0.018, t$-test; Figure 3a,b). A linear regression model of the $Z B T B 20$ region run on the independent case-control samples adjusting for age, body mass index (BMI) and smoking status retained significance $(P=0.0487)$. ZBTB20 contains the second most significantly differentially methylated region identified in the meta-analysis, with an increased methylation level in cases $(P=0.00048$, Bonferoni adjusted for approximately $11 \mathrm{M}$ tests). The gene plays an essential role in the specification of the Cornu Ammonis-1 (CA1) field identity in the developing hippocampus. The RPM (reads per millions) value of the DMR is consistently higher in the depressed cohort in relation to the control (Figure 3c).

\section{Observed methylation changes do not relate to anti- depressant use}

The identified DMRs associated with MDD could reflect the consequence rather than the cause of the disorder. One possible consequence is use of anti-depressant medication, which was assessed as a confounder for the UK MZT pairs, for whom a record of drug usage was available. Two additional linear mixed models were calculated. The first included those individuals taking antidepressant medication as an additional factor, the second eliminated twin pairs where the depressed twin was taking medication. Both produced results relatively consistent with the UK linear mixed model, suggesting that the observed methylation differences are not caused by antidepressant medication based on data available to us (Tables S1, S2 and S3 in Additional file 1). ZBTB2O is significantly associated with MDD to an unadjusted $P$-value of $2.99 \times 10^{-7}$ if anti-depressant medication is included in the regression model and significant to a $P$-value of $1.28 \times 10^{-5}$ even if all depressed individuals taking medication are removed from the study. The $\beta$ coefficient of the DMR also remains consistent with the full linear model giving a $\beta$ value of 1.073. Two other linear models, one where the anti-depressant medication was included as a co-factor and one where the model removed medicated twin pairs completely, produced $\beta$ coefficients of 1.078 and 1.082, respectively. No association was observed between cell count and calculated methylation levels for the most significant DMRs in the UK linear mixed model (see Materials and methods).

Our MeDIP-seq data indicated that twins with MDD had a significantly increased variance in methylation when compared with their unaffected co-twin. Comparison of variance in global methylation between the depressed twin 


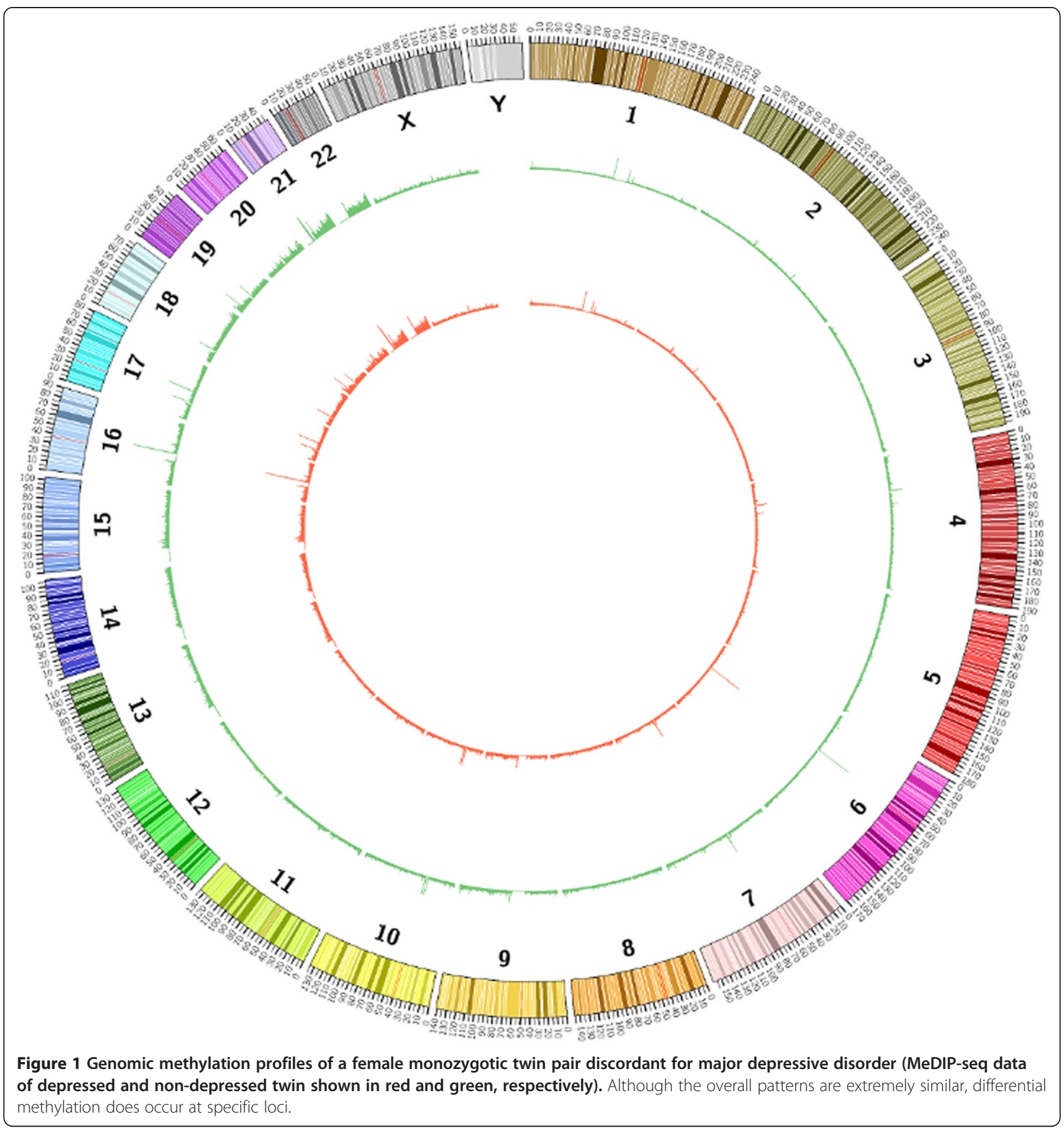

and their unaffected co-twin revealed a highly significant increased genome-wide variance in twins with MDD in both the UK and Australian cohorts $\left(P<2.2 \times 10^{-16}\right.$ in both datasets). This is in agreement with Byrne et al. [24], who used the much sparser $450 \mathrm{k}$ array but also reported increased variance of methylation in the affected twin in a cohort of 12 MZT pairs, a subsample of the current Australian cohort. Byrne et al. failed to find any genomewide significant DMRs in the 12 MZT pairs discordant for MDD. This could be the result of a limited sample size and/or the usage of the $450 \mathrm{k}$ array, which has a much lower resolution than MeDIP-seq [25].

Several mouse studies have already demonstrated the importance of $Z B T B 20$ for normal hippocampal function. ZTBT20 targets hippocampal neurons as well as cerebellum granule cells [26], consistent with our observation of a high ZTBT20 expression in the hippocampal, cerebellum and white matter regions of the brain. Conditionally deleting ZBTB2O specifically in mature CA1 pyramidal neurons impairs long-term potentiation and NMDA receptor 
Table 1 Meta-analysis of 54 UK and 46 Australian blood samples using a fixed effects model approach

\begin{tabular}{|c|c|c|c|c|c|c|c|c|c|}
\hline Chromosome & Start & Stop & $P$-value & Adjusted $P$-value & Gene start & Gene stop & Gene name & Distance & Description \\
\hline Chr5 & 63738001 & 63738501 & 1.75E-11 & 0.00019 & 63802451 & 63908121 & RGSTBP & 63950 & Regulator of G-protein signaling 7 binding protein \\
\hline Chr3 & 114618751 & 114619251 & 4.34E-11 & 0.00048 & 114056946 & 114866127 & ZBTB20 & - & Zinc finger and BTB domain containing 20 \\
\hline Chr1 & 120633001 & 120633501 & $1.12 \mathrm{E}-10$ & 0.00125 & 120454175 & 120612317 & $\mathrm{NOTCH} 2$ & 20684 & Notch homolog 2 (Drosophila) \\
\hline Chr9 & 84715501 & 84716001 & 1.47E-10 & 0.00164 & 84603686 & 84610171 & FL46321 & 105330 & FAM75-like protein FL46321 \\
\hline Chr1 & 9845751 & 9846251 & $1.58 \mathrm{E}-10$ & 0.00176 & 9789078 & 9884550 & CLSTN1 & - & Calsyntenin 1 \\
\hline Chr9 & 88306501 & 88307001 & $2.02 \mathrm{E}-10$ & 0.00225 & 88161453 & 88356944 & AGTPBP1 & - & ATP/GTP binding protein 1 \\
\hline Chr3 & 36140001 & 36140501 & 4.93E-10 & 0.00549 & 36422096 & 36589496 & STAC & 281595 & SH3 and cysteine rich domain \\
\hline Chr7 & 17309251 & 17309751 & 1.35E-09 & 0.01503 & 17338275 & 17385775 & $A H R$ & 28524 & Aryl hydrocarbon receptor \\
\hline Chr1 & 166550001 & 166550501 & $1.56 \mathrm{E}-09$ & 0.01737 & 166573152 & 166594473 & FMO9P & 22651 & Flavin containing monooxygenase 9 pseudogene \\
\hline Chr3 & 66970001 & 66970501 & 1.69E-09 & 0.01881 & 67048726 & 67061632 & KBTBD8 & 78225 & Kelch repeat and BTB (POZ) domain \\
\hline Chr12 & 132823251 & 132823751 & $2.30 \mathrm{E}-09$ & 0.02560 & 132680916 & 132905905 & GALNT9 & - & UDP-N-acetyl-alpha-D-galactosamine \\
\hline Chr2 & 101764501 & 101765001 & 2.91E-09 & 0.03239 & 101623689 & 101767846 & $T B C 1 D 8$ & - & TBC1 domain family, member 8 \\
\hline Chr12 & 57688251 & 57688751 & 3.37E-09 & 0.03752 & 57647547 & 57704246 & R3HDM2 & - & R3H domain containing 2 \\
\hline Chr2 & 221655001 & 221655501 & 3.42E-09 & 0.03807 & 222282746 & 222437010 & EPHA4 & 627245 & EPH receptor A4 \\
\hline Chr4 & 182369251 & 182369751 & 3.63E-09 & 0.04041 & 181985242 & 182080302 & LINC00290 & 288949 & Long intergenic non-protein coding RNA 290 \\
\hline Chr6 & 24236501 & 24237001 & $3.88 \mathrm{E}-09$ & 0.04319 & 24171982 & 24358280 & $D C D C 2$ & - & Double cortin domain containing 2 \\
\hline Chr4 & 15620251 & 15620751 & 4.30E-09 & 0.04787 & 15606006 & 15657035 & FBXL5 & - & F-box and leucine-rich repeat protein 5 \\
\hline Chr4 & 170932501 & 170933001 & 4.65E-09 & 0.05177 & 170907747 & 170947429 & MFAP3L & - & Microfibrillar-associated protein 3-like \\
\hline Chr16 & 55912001 & 55912501 & 4.93E-09 & 0.05488 & 55880065 & 55989943 & CES5A & - & Carboxylesterase $5 \mathrm{~A}$ \\
\hline Chr12 & 126885001 & 126885501 & 5.67E-09 & 0.06312 & 126927026 & 126957331 & LOC100128554 & 41525 & Uncharacterized LOC100128554 \\
\hline Chr10 & 22007501 & 22008001 & $6.22 \mathrm{E}-09$ & 0.06924 & 21823100 & 22032559 & MLLT10 & - & Myeloid/lymphoid leukemia \\
\hline Chr1 & 172293751 & 172294251 & 6.57E-09 & 0.07314 & 171810620 & 172381857 & DNM3 & - & Dynamin 3 \\
\hline Chr1 & 75392751 & 75393251 & $6.61 \mathrm{E}-09$ & 0.07358 & 75198861 & 75232360 & TYW3 & 160391 & tRNA-yW synthesizing protein 3 \\
\hline
\end{tabular}

The nearest gene feature to a DMR is shown, DMRs occurring within a coding region are shown in bold. Bonferoni adjusted $P$-values with a significance $<0.01$ are also shown in bold. 


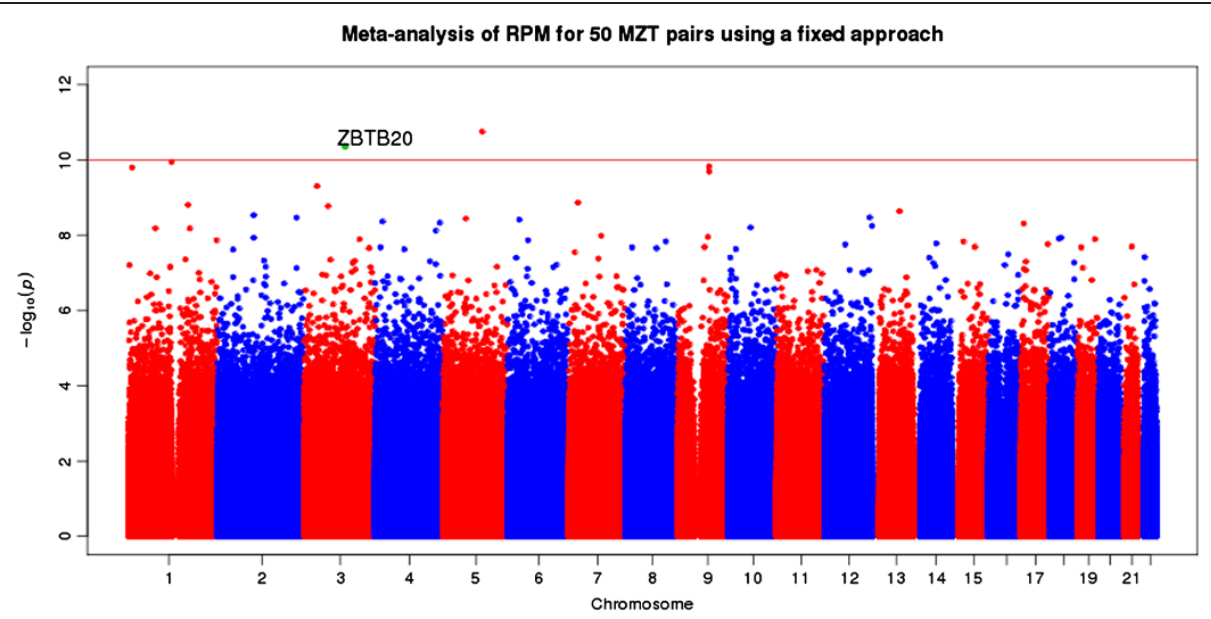

Figure 2 Manhattan plot showing the $P$-values of approximately $10 \mathrm{M} 500 \mathrm{bp}$ bins from the meta analysis with the ZBTB20 DMR identified in the plot.

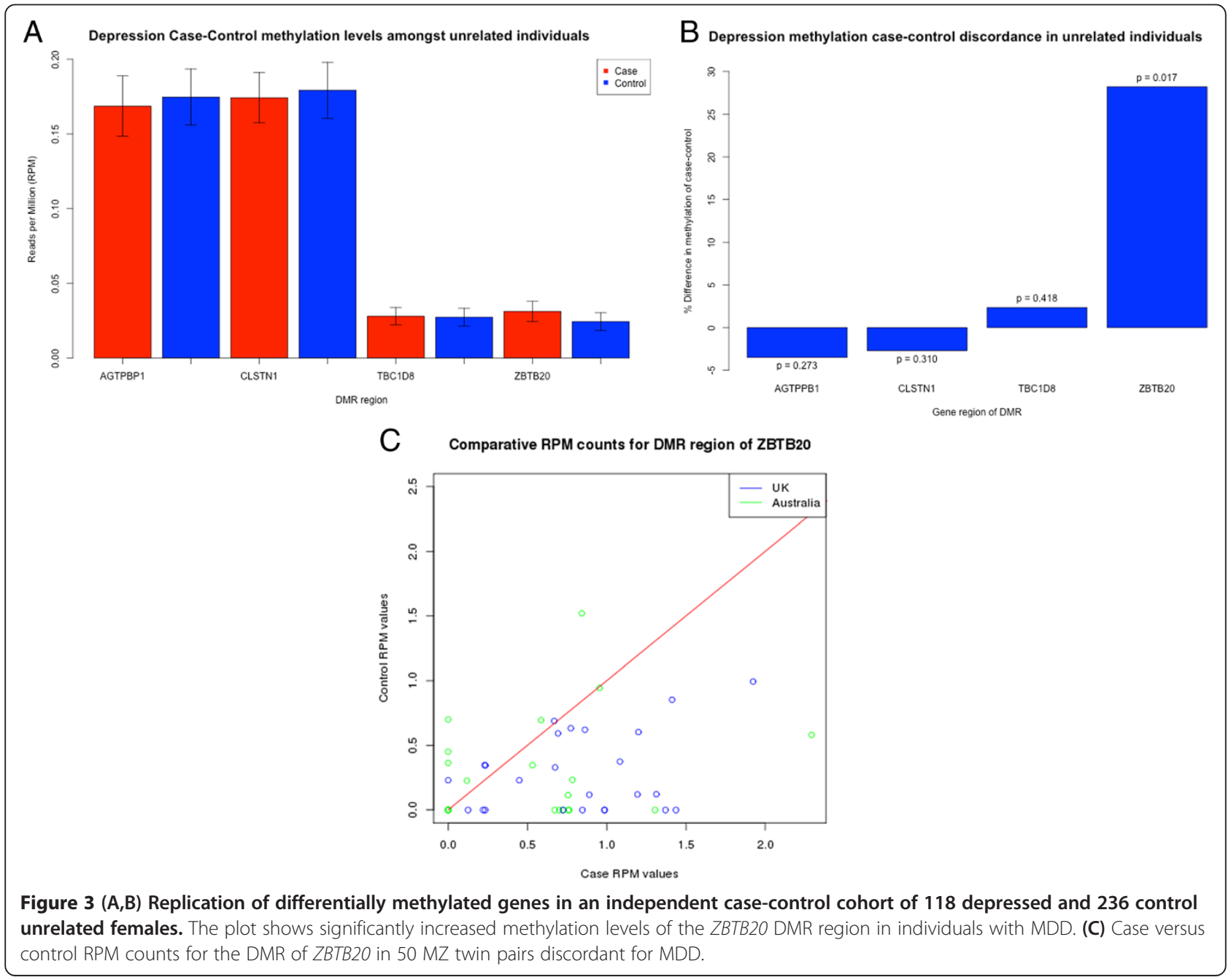


(NMDAR)-mediated excitatory post-synaptic currents [27]. ZBTB20 is also crucial for the regionalization and volume of the archicortex [28], which plays a role in depression. In mice, mis-expression of ZBTB20 causes the development of a compact homogenous pyramidal cell layer within the hippocampal region, which is linked to behavioural abnormalities [29].

Magnetic resonance imaging scans of MZT pairs discordant for MDD identified volume reduction in the left posterior hippocampal region in the depressed co-twin [30]. In MDD, the dentate gyrus, and pyramidal neuron soma size is significantly decreased [31-34], suggesting that altered neuronal development rather than outright neuronal loss is responsible for the structural abnormalities linked to depression [35]. This is consistent with the pattern of reduced hippocampal volume and impaired regionalization suggested by the mouse model. The DMR of ZBTB2O we identified is hypermethylated in subjects with MDD and occurs within an identified splice region, which may have the effect of creating distinct isoforms based upon the specific methylation profile. $Z B T B 20$ is also functionally related to the only SNP so far associated with MDD to a genome-wide significance in a genome-wide association study (common SNP rs1545843 $($ minor allele frequency $=0.41)$ ) [36] occurring within the gene SLC6A15, which like ZTBT20 is associated with hippocampal structure. Down-regulation of SLC6A15 causes a reduced hippocampal volume (an effect that was replicated in stress-susceptible mice) and lower SLC6A15 expression in hippocampus reduces neural integrity and excitatory neurotransmission in the brain.

\section{ZBTB20 shows specific gene expression in the hippocampus}

Gene expression data of 932 brain samples from 10 different brain regions from 101 unrelated individuals taken from the Edinburgh Brain Bank (see Materials and methods) showed that, in the overall dataset, ZBTB20 is highly expressed in the hippocampal, cerebellum and white matter regions of the brain and lowly expressed in the frontal, occipital and temporal cortex (Figure S1 in Additional file 1). A weighted gene co-expression network analysis using WGCNA [37] generated a hippocampus ZBTB20-cointaining module (with a total $\mathrm{N}=216$ genes) that was unique to the tissue ( $Z$ summary preservation statistic $<10$ ), suggesting that $Z B T B 20$ is co-expressed with a unique set of genes in the hippocampus, suggesting it has a key function in its regulation (Figure 4).

\section{RNA-seq data for MDD from NIMH Center for Collaborative Genomic Studies on Mental Disorders}

Data were adjusted for the confounding covariates BMI, smoking, age, gender and various medication intake indicators. No association between total gene expression level of
ZBTB20 and MDD was observed ( $P$-value $>0.5)$. However, two non-standard exons identified within ZBTB2O transcript variants (exon 33 in ENST00000463890 and exon 45 in ENST00000470556) are associated with unadjusted $P$-values of 0.041 and 0.04 , respectively. For these two exons, we visually inspected the per-base read distribution in cases and controls, and observed a smooth shift of mean expression levels across all bases in each case (Figure S2 in Additional file 1). Both exons 33 and 45 are downstream of the DMR and are located at 114099729-114099787 and 114137901-114138014, respectively. In the mouse homologue gene, Zbtb20, two isoforms of the gene were shown to have distinct roles in the development of the hippocampus [29]. The expression of non-standard exons in ZBTB2O may similarly have an impact on the development and regionalization of the human hippocampus.

\section{Limitations}

Several possible limitations to our study should be noted. We used whole blood rather than brain samples of discordant MZT pairs to identify methylation differences associated with MDD, which is sub-optimal but clearly more accessible from living patients. Furthermore, if epigenetic studies are to be of clinical use, they will ultimately have to rely upon peripheral tissue biomarkers such as buccal, gut and white blood cells. However, a previous study comparing the methylation status of pre-mortem blood and post-mortem brain tissue [2] showed that significant variation in the methylation profile of brain tissue can be reflected in blood. Also, recent studies have shown that DMRs associated with both chronic pain [38] and ageing are similar in brain and blood tissue [39]. Although in the UK sample analyses of anti-depressant treatment could not explain the observed associations, other potential factors can not be entirely eliminated. For example, birth weight and chorionicity of the twin pair are possibly correlated with adult methylation levels [40,41], but that information was not available for the MZT pairs included in the study. Another potential confounding factor in the study was that the samples were predominately female. Our RNA-seq validation data set was more evenly distributed than the initial study with $30 \%$ of the subjects male (103 in case, 171 in control). It should, however, be noted that the RNA-seq association is only of nominal significance and would not retain significance if adjusted for multiple testing.

\section{Conclusions}

Previous studies looking for genetic and epigenetic associations with MDD have largely been unsuccessful, possibly due to the complexity of the phenotype or the heterogeneity of the population. A meta-analysis of 50 pairs of $\mathrm{MZ}$ 


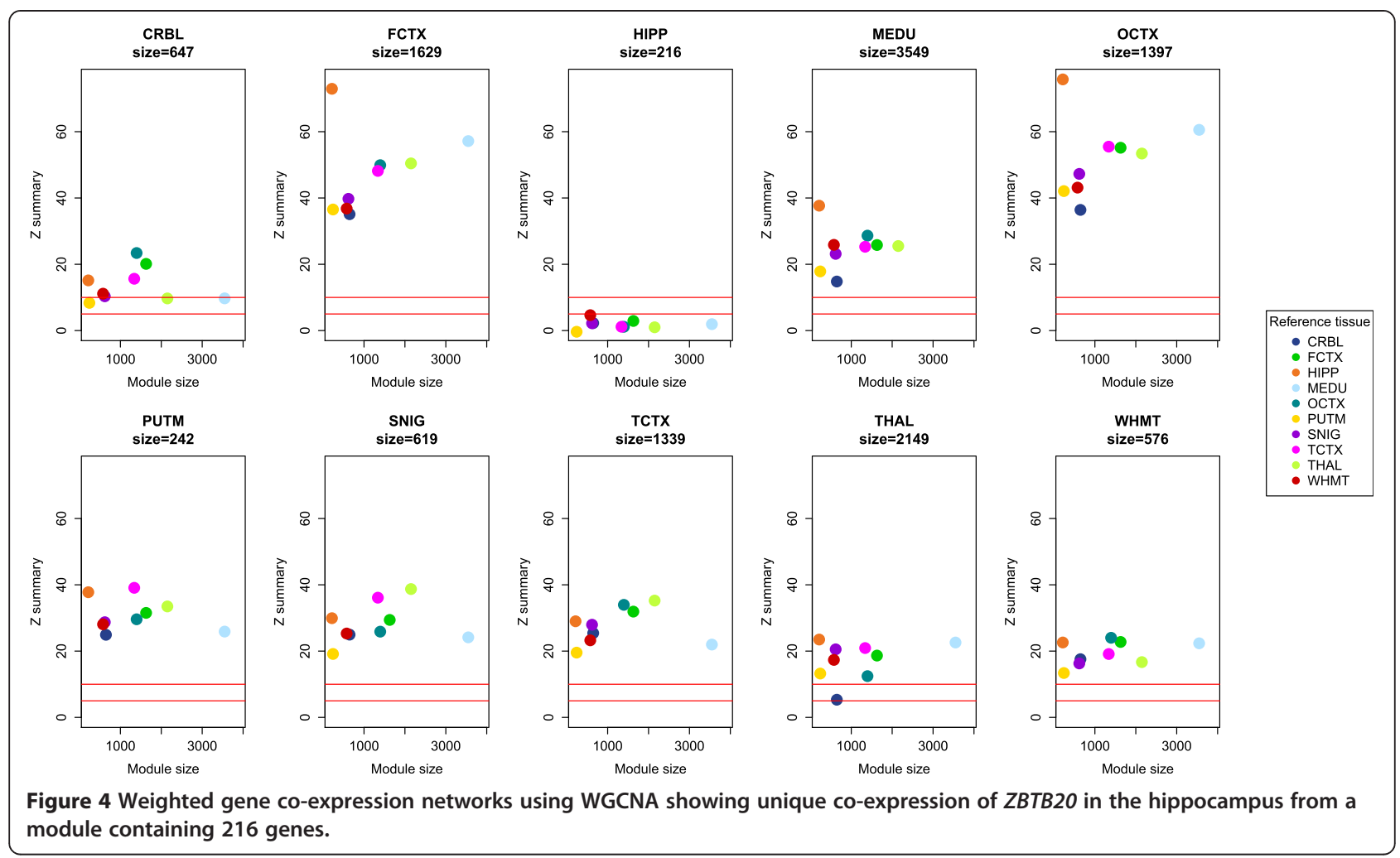

twins discordant for depression has identified a region of the genome consistently hypermethylated in the depressed cohort, a result that was replicated in an unrelated case-control population. Excitingly, the DMR occurs within the coding region of the ZBTBT20 gene, which is associated with the structural integrity of the hippocampus. This supports current research regarding the etiology of MDD, which suggests it may be driven by a disorder of neuron structure [42-44]. Analysis of brain tissue and expression data in the region also supports a model whereby misexpression of ZBTB20 may be associated with depression. This study represents the largest and most comprehensive study so far of genome-wide methylation differences in MZ pairs discordant for MDD and suggests that larger collaborative epigenetic twins studies are cost-effective and could provide even more clues to the etiology of complex traits.

\section{Materials and methods}

The overall design was a meta-analysis of whole blood genome-wide methylation in two cohorts of MZT pairs discordant for MDD, followed by replication in an independent case-control group and exploration of expression and methylation signals in independent brain tissue samples.

\section{Included subjects}

The 27 MZT pairs $(n=54)$ of the UK samples were selected from the TwinsUK Registry. The 54 participants were all females aged 23 to 73 years, of European ancestry and had no other psychiatric condition nor had they been diagnosed with any known neurodegenerative disorder. The study was approved by the St Thomas' Hospital Research Ethics Committee (REC reference: EC04/ 015). All participants in the study provided written informed consent in accordance with the St Thomas' Hospital Local Ethics Committee. UK twin pairs completed the Composite International Diagnostic Interview questionnaire [45]. A diagnosis of MDD was constructed from these questionnaires according to the DSM-IV criteria [46]. Whole blood samples were collected from the twins and stored at $-80^{\circ} \mathrm{C}$ in EDTA tubes. DNA was extracted from $2 \times 6 \mathrm{ml}$ EDTA blood using the Nucleon Genomic DNA Extraction Kit BACC3 and stored at $-20^{\circ} \mathrm{C}$ in TE Buffer.

The 23 MZT pairs of the Australian samples $(n=46)$ were drawn from the Australian Twin Registry. The 46 participants comprised 7 male and 16 female MZ twin pairs aged 25 to 73 years. Seven pairs were discordant for smoking and a partially overlapping set of seven twin pairs was discordant for alcohol dependence. The study was approved by the Human Research Ethics Committee of the Queensland Institute of Medical Research. The 
assessment of Australian MZT pairs included a diagnostic telephone interview, adapted from the Semi-Structured Assessment for the Genetics of Alcoholism (SSAGA) [47]. The SSAGA is a comprehensive psychiatric interview that was designed to assess life-time psychiatric disorders in adults according to DSM-III-R but subsequently updated to DSM-IV criteria and modified for use as a telephone survey instrument in Australia (SSAGA-OZ). SSAGA also assesses history of alcohol dependence and tobacco smoking with questions derived from the Composite International Diagnostic Interview [48]. Structured interviews were administered by trained telephone interviewers, closely supervised by a clinical psychologist. DNA was extracted from whole blood using a salt extraction method [49].

\section{Sample preparation for MeDIP-seq}

All sample preparation and MeDIP-sequencing was performed by the BGI-Shenzhen, Shenzhen, China. Extracted DNA was fragmented using a Covaris sonication system and sequencing libraries were prepared from $5 \mu \mathrm{g}$ fragmented genomic DNA. End repair, $<\mathrm{A}>$ base addition and adaptor ligation steps were performed using Illumina's Single-End DNA Sample Prep kit. Adaptor-ligated DNA was immunoprecipitated by anti- $5 \mathrm{mC}$ using a commercial antibody (Diagenode), and MeDIP products were validated by quantitative PCR. MeDIP DNA was purified with ZYMO DNA Clean \& Concentrator-5 columns, and amplified using adaptor-mediated PCR. DNA fragments between 220 and 320 bp in size were gel-excised, and amplification quality and quantity were evaluated by Agilent BioAnalyzer analysis. The libraries were subjected to highly parallel $50 \mathrm{bp}$ single-end sequencing on the Illumina HiSeq platform.

\section{Sequencing quality control and alignment}

From the raw fastq files, Illumina quality scores were converted into Sanger Phred quality scores using MAQ [50]. Quality control was performed on the raw sequence data using in-house scripts and FastQC [51]. After stringent quality control, an average of 19 million uniquely mapped $50 \mathrm{bp}$ reads were obtained from each of the 100 samples. Alignment to hg19 was performed using the Burrows-Wheeler algorithm [52]. The MEDIPS package [53] was used to calculate RPM scores by defining bin sizes of $500 \mathrm{bp}$ with an overlap of $250 \mathrm{bp}$ across the genome (Figure 1). The total number of $500 \mathrm{bp}$ bins generated by the MEDIPS packages was $12,145,229$. The number of bins was filtered to include only bins where more than $10 \%$ of samples had a read coverage greater than 0 . For the UK samples, this reduced the number to 11,132,286 bins, for the Australian samples to 10,480,864. For both data sets, the raw FastQ files and calculated RPM scores from the aligned data are available from the Gene Expression Omnibus (GEO) database [54]. The UK samples are Study ID GSE54222 and the Australian samples are Study ID GSM1313979.

\section{Linear mixed effect models}

A linear mixed effect model was fitted for the RPM values of each $500 \mathrm{bp}$ bin using the R package lmer [55]. Models were derived separately for the UK and Australian cohorts, reflecting the different fixed and random effects that needed to be incorporated for the two datasets. For the UK dataset, the linear mixed effect model incorporated depression status, age, BMI, smoking and alcohol consumption as fixed effects predictors [40,56-58] and twin pair as random effect (Table S1 in Additional file 1). In order to determine whether the discordant methylation could be a result of anti-depressant medication, two further linear mixed models were calculated. The first included those individuals taking anti-depressant medication as an additional factor, the second eliminated twin pairs where the depressed twin was taking medication from the study (Tables S2 and S3 in Additional file 1). Research has suggested that heterogeneity in whole blood cell counts could confound estimates of DNA methylation levels $[59,60]$. Cell count data were available for 21 twin pairs in the UK dataset; the top hits from the linear mixed model were analysed for evidence of association with cell counts of lymphocytes, neutrophils, eosinophils, monocyte, and total white blood and blood cell counts. For both data sets, the variance in methylation for cases and controls was compared for each bin.

The linear mixed effect model for the Australian dataset also incorporated depression status, age, tobacco addiction (yes/no) and alcohol dependence (yes/no) as fixed effects and twin pair as a random effect; medication data were not available for these samples. Sex was also incorporated as a fixed effect, but BMI was excluded, as this information was unavailable for four twin pairs. We investigated the effect of BMI as a covariate by fitting a second linear mixed effect model for the subset of 19 Australian twin pairs with available BMI information. Incorporating BMI as a fixed effect had only a minor effect on the $P$-values observed for the DMRs shown in Table S4 in Additional file 1.

\section{Meta-analysis}

As the UK and Australian datasets were drawn from different populations and modeled with different fixed effects, the data were integrated through a meta-analysis. A fixed effect inverse variance meta-analysis was carried out on all approximately $11 \mathrm{M}$ bins of the UK and Australian datasets, using GWAMA [61]. P-values were Bonferoni adjusted to correct for multiple testing. We only present results for DMRs that show no strong evidence for heterogeneity in the meta-analysis as evaluated by the Cochran's 
Q statistic (Cochran's Q $P>0.05)$ [62] and the $\mathrm{I}^{2}$ statistic $\left(\mathrm{I}^{2}<0.75\right)[63]$.

\section{Replication in independent case-control cohort of 354 unrelated females}

Differentially methylated genes identified in the metaanalysis of UK and Australian MZT pairs were evaluated with the existing scientific literature to select for likely MDD-related DMRs. Four DMRs were located within genes related to the pathology of MDD and selected for replication (see Results). For an independent case-control replication we included blood MeDIP-seq data of 354 unrelated, age-matched females from the EpiTwin project, 118 suffering from MDD and 236 controls. MeDIP-seq data of 118 cases and 236 controls were compared by $t$-test (RPM values of each $500 \mathrm{bp}$ bin).

\section{Postmortem brain expression data obtained from the UK Brain Expression Consortium}

The four DMRs selected for replication were also compared with an independent expression dataset of 932 postmortem brain samples collected from the Edinburgh Brain Bank as part of the UK Brain Expression Consortium [64]. Expression data were generated with the Affymetrix GeneChip Human Exon 1.0 ST Array and the dataset contains 932 brain samples of 10 different brain regions obtained from 101 unrelated individuals (24 male and 77 female) aged from 16 to 83 years. The 10 brain regions are cerebellum, frontal cortex, hippocampus, medulla, occipital cortex, putamen, substantia niagra, temporal cortex, thalamus and intralobular white matter. The WGCNA R package was used to analyze the data for incidence of conserved co-expression gene networks [65].

\section{Case-control MDD RNA-seq data}

The cohort is of European ancestry and contains 463 individuals with recurrent MDD and 459 controls. A detailed description of RNA-sequence and phenotype data for this cohort is provided elsewhere [66,67]. RNA-sequencing was performed using whole-blood, with an average yield of 70 million reads per individual (50 or $51 \mathrm{bp}$, singleended). Reads were mapped to the NCBI v37 H. sapiens reference genome using TopHat [68].Gene expression data were directly obtained from the previous study on this cohort [66]. Gene-level expression was quantified using HTSeq [69]. Additionally, we used samtools mpileup to quantify reads at each exonic position within the gene [70]. Only uniquely aligned reads with base quality of at least 30 were used for quantification. We then aggregated reads within the start and end points of each distinct exon identified in ENSEMBL Homo sapiens gene annotation, and normalized by the total read depth of each library. Total gene expression and exon expression of ZBTB2O were tested for association with MDD status.
Associating testing followed the procedure reported previously for this cohort: a logistic regression likelihood ratio test was used to test for association between expression levels and MDD status while accounting for environmental, demographic, and medication intake covariates [66]. The list of covariates include age, gender, BMI, smoking status, cholesterol and blood pressure medication intake indicators. Genotype, raw RNA-seq, quantified expression, and covariate data are available by application through the NIMH Center for Collaborative Genomic Studies on Mental Disorders. Instructions for requesting access to data can be found at NIMH Repository and Genomics Resource [71] and inquiries should reference the 'Depression Genes and Networks study' (D Levinson, PI) [66].

\section{Additional file}

Additional file 1: Table S1. linear mixed model on TwinsUK dataset RPM values showing values for age, depression, smoking, alcohol and BMI. The nearest gene feature to a DMR is shown; DMRs occurring within a coding region are shown in bold. Table S2. linear mixed model on RPM factoring values for age, depression, smoking, alcohol, BMI and anti-depressant medication. The nearest gene feature to a DMR is shown, DMRs occurring within a coding region are shown in bold. Table S3. linear mixed model on RPM factoring values for age, depression, smoking, alcohol and BMI removing twin pairs taking anti-depressant medication. The nearest gene feature to a DMR is shown; DMRs occurring within a coding region are shown in bold. Table S4. linear mixed model on Queensland dataset RPM values showing values for age, depression, smoking, alcohol and BMI. The nearest gene feature to a DMR is shown; DMRs occurring within a coding region are shown in bold. Figure S1. averaged expression values of the ZBTB20 gene across 10 brain regions. Figure S2. ZBTBT20 exon 33 and exon 45 case-control comparison for the RNA-seq expression data.

\section{Abbreviations}

BMI: body mass index; bp: base pair; CA1: Cornu Ammonis-1;

DMR: differentially methylated region; DSM-IV: Diagnostic and Statistical Manual of Mental Disorders, Fourth Edition; MDD: major depressive disorder; MeDIP-seq: methylated DNA immunoprecipitation combined with ultra-deep sequencing; MZT: monozygotic twin; PCR: polymerase chain reaction; RPM: reads per millions; SNP: single nucleotide polymorphism; SSAGA: Semi-Structured Assessment for the Genetics of Alcoholism.

\section{Competing interests}

The authors declare that they have no competing interests.

\section{Authors' contributions}

$F G, H W, H L, Y L$ and JW were responsible for the sequencing and quality control of the MeDIP-seq. JM, ED and TM provided provided additional validation data. $A B, S M$ and $X Z$ provided and analyzed the RNA-seq data. UK Brain Expression Consortium provided gene expression brain data. KJW, P-CT and DAC provided twin data for the UK cohort. AH, EB and NRW provided twin data for the Australian cohort. Analysis and meta-analysis of both datasets was carried out by MND, LK and JTB. MND, LK, JTB, TDS and NGM drafted the manuscript. All authors read and approved the final manuscript.

\section{Acknowledgements}

UK: we gratefully acknowledge the assistance of Lynn Cherkas in the selection of the Twin Samples and Stuart Newman for his assistance in the storage and processing of the methylomic data. We thank the twins for their voluntary contribution to this project. The study was funded by the Wellcome Trust; European Community's Seventh Framework Programme (FP7/2007-2013). The study also receives support from the National Institute for Health Research (NIHR) Clinical Research Facility at Guy's \& St Thomas' 
NHS Foundation Trust and NIHR Biomedical Research Centre based at Guy's and St Thomas' NHS Foundation Trust and King's College London. Matthew Davies is supported by the EU FP7 grant EuroBATS (No. 259749). Tim Spector is an NIHR senior Investigator and is holder of an ERC Advanced Principal Investigator award. Further funding support for this project was obtained from the European Research Council (project number 250157). The members of the UK Brain Expression Consortium (UKBEC) are: (1) Department of Molecular Neuroscience, UCL Institute of Neurology, London, UK: John A Hardy, Mina Ryten, and Daniah Trabzuni; (2) Department of Medical and Molecular Genetics, King's College London, UK: Michael E Weale, Adaikalavan Ramasamy and Paola Forabosco; (3) Department of Pathology, The University of Edinburgh, Wilkie Building, Teviot Place, Edinburgh, UK: Colin Smith and Robert Walker. Australia: funding for phenotype and blood collection was from NHMRC grants to Nick Martin and NIH grants to Andrew Heath and Pamela Madden. We thank David Smyth for database management, Lisa Bowdler for sample preparation, and the twins for their cooperation.

\section{Author details}

'Department of Twin Research \& Genetic Epidemiology, King's College London, St Thomas' Hospital Campus, Westminster Bridge Road, London SE1 7EH, UK. ${ }^{2}$ Queensland Institute of Medical Research, Brisbane, QLD 4006, Australia. ${ }^{3}$ BGI-Shenzhen, Shenzhen 518083, China. ${ }^{4}$ SGDP Centre, Institute of Psychiatry, King's College London, London SE5 8AF, UK. ${ }^{5}$ Medical School, University of Exeter, Exeter EX1 2LU, UK. ${ }^{6}$ Queensland Brain Institute, University of Queensland, St Lucia, QLD 4072, Australia. 'Stanford University, Stanford, CA 94305, USA.

Received: 19 November 2013 Accepted: 2 April 2014 Published: 2 April 2014

\section{References}

1. Yuen RK, Neumann SM, Fok AK, Penaherrera MS, McFadden DE, Robinson WP, Kobor MS: Extensive epigenetic reprogramming in human somatic tissues between fetus and adult. Epigenetics Chromatin 2011, 4:7.

2. Davies MN, Volta M, Pidsley R, Lunnon K, Dixit A, Lovestone S, Coarfa C, Harris RA, Milosavljevic A, Troakes C, Al-Sarraj S, Dobson R, Schalkwyk LC, Mill $\mathrm{J}$ : Functional annotation of the human brain methylome identifies tissue-specific epigenetic variation across brain and blood. Genome Biol 2012, 13:R43.

3. Mill J, Petronis A: Molecular studies of major depressive disorder: the epigenetic perspective. Mol Psychiatry 2007, 12:799-814.

4. Samaco RC, Neul JL: Complexities of Rett syndrome and MeCP2. J Neurosci 2011, 31:7951-7959.

5. Mill J, Tang T, Kaminsky Z, Khare T, Yazdanpanah S, Bouchard L, Jia P, Assadzadeh A, Flanagan J, Schumacher A, Wang SC, Petronis A: Epigenomic profiling reveals DNA-methylation changes associated with major psychosis. Am J Hum Genet 2008, 82:696-711.

6. Mehta D, Klengel T, Conneely KN, Smith AK, Altmann A, Pace TW, Rex-Haffner M, Loeschner A, Gonik M, Mercer KB, Bradley B, Muller-Myhsok B, Ressler KJ, Binder EB: Childhood maltreatment is associated with distinct genomic and epigenetic profiles in posttraumatic stress disorder. Proc Natl Acad Sci U S A 2013, 110:8302-8307.

7. Sun $\mathrm{H}$, Kennedy PJ, Nestler EJ: Epigenetics of the depressed brain: role of histone acetylation and methylation. Neuropsychopharmacology 2013, 38:124-137.

8. Booij L, Wang D, Levesque ML, Tremblay RE, Szyf M: Looking beyond the DNA sequence: the relevance of DNA methylation processes for the stress-diathesis model of depression. Philos Trans R Soc Lond B Biol SCi 2013, 368:20120251

9. Kang HJ, Kim JM, Stewart R, Kim SY, Bae KY, Kim SW, Shin IS, Shin MG, Yoon JS: Association of SLC6A4 methylation with early adversity, characteristics and outcomes in depression. Prog Neuropsychopharmacol Biol Psychiatry 2013, 44:23-28.

10. Fuchikami M, Morinobu S, Segawa M, Okamoto Y, Yamawaki S, Ozaki N, Inoue T, Kusumi I, Koyama T, Tsuchiyama K, Terao T: DNA methylation profiles of the brain-derived neurotrophic factor (BDNF) gene as a potent diagnostic biomarker in major depression. PLoS One 2011, 6:e23881.

11. Ripke S, Wray NR, Lewis CM, Hamilton SP, Weissman MM, Breen G, Byrne EM, Blackwood DH, Boomsma DI, Cichon S, Heath AC, Holsboer F, Lucae S, Madden PA, Martin NG, McGuffin P, Muglia P, Noethen MM, Penninx BP, Pergadia ML, Potash JB, Rietschel M, Lin D, Muller-Myhsok B, Shi J, Steinberg
$\mathrm{S}$, Grabe HJ, Lichtenstein P, Magnusson P, Perlis RH, et al: A mega-analysis of genome-wide association studies for major depressive disorder. Mol Psychiatry 2013, 18:497-511.

12. Sullivan PF, Neale MC, Kendler KS: Genetic epidemiology of major depression: review and meta-analysis. Am J Psychiatry 2000, 157:1552-1562.

13. McGuffin P, Katz R, Watkins S, Rutherford J: A hospital-based twin register of the heritability of DSM-IV unipolar depression. Arch Gen Psychiatry 1996, 53:129-136.

14. Bierut $L$, Heath AC, Bucholz KK, Dinwiddie SH, Madden PA, Statham DJ, Dunne MP, Martin NG: Major depressive disorder in a community-based twin sample: are there different genetic and environmental contributions for men and women? Arch Gen Psychiatry 1999, 56:557-563.

15. Hodes GE: Sex, stress, and epigenetics: regulation of behavior in animal models of mood disorders. Biol Sex Differ 2013, 4:1.

16. Sabunciyan S, Aryee MJ, Irizarry RA, Rongione M, Webster MJ, Kaufman WE, Murakami P, Lessard A, Yolken RH, Feinberg AP, Potash JB: Genome-wide DNA methylation scan in major depressive disorder. PLoS One 2012, 7:e34451.

17. Uddin M, Koenen KC, Aiello AE, Wildman DE, De Los Santos R, Galea S: Epigenetic and inflammatory marker profiles associated with depression in a community-based epidemiologic sample. Psychol Med 2011, 41:997-1007.

18. Yang BZ, Zhang H, Ge W, Weder N, Douglas-Palumberi H, Perepletchikova F, Gelernter J, Kaufman J: Child abuse and epigenetic mechanisms of disease risk. Am J Prev Med 2013, 44:101-107.

19. Oberlander TF, Weinberg J, Papsdorf M, Grunau R, Misri S, Devlin AM: Prenatal exposure to maternal depression, neonatal methylation of human glucocorticoid receptor gene (NR3C1) and infant cortisol stress responses. Epigenetics 2008, 3:97-106.

20. Oh JE, Chambwe N, Klein S, Gal J, Andrews S, Gleason G, Shaknovich R, Melnick A, Campagne F, Toth M: Differential gene body methylation and reduced expression of cell adhesion and neurotransmitter receptor genes in adverse maternal environment. Trans/ Psychiatry 2013, 3:e218.

21. Melas PA, Wei Y, Wong CC, Sjoholm LK, Aberg E, Mill J, Schalling M, Forsell $Y$, Lavebratt C: Genetic and epigenetic associations of MAOA and NR3C1 with depression and childhood adversities. Int I Neuropsychopharmacol 2013, 16:1513-1528.

22. Jiao J, Opal MD, Dulawa SC: Gestational environment programs adult depression-like behavior through methylation of the calcitonin gene-related peptide gene. Mol Psychiatry 2012, 18:1273-1280.

23. Mill J, Dempster E, Caspi A, Williams B, Moffitt T, Craig I: Evidence for monozygotic twin (MZ) discordance in methylation level at two $\mathrm{CpG}$ sites in the promoter region of the catechol-O-methyltransferase (COMT) gene. Am J Med Genet B Neuropsychiatr Genet 2006, 141B:421-425.

24. Byrne E, Carillo-Roa T, Henders AK, Bowdler L, McRae AF, Heath AC, Martin NG, Montgomery GW, Krause L, NR W: Monozygotic twins affected with major depressive disorder have greater variance in methylation than their unaffected co-twin. Transl Psychiatry 2013, 3:e269.

25. Clark C, Palta P, Joyce CJ, Scott C, Grundberg E, Deloukas P, Palotie A, Coffey $\mathrm{AJ}$ : A comparison of the whole genome approach of MeDIP-seq to the targeted approach of the Infinium HumanMethylation450 BeadChip((R)) for methylome profiling. PLoS One 2012, 7:e50233.

26. Mitchelmore C, Kjaerulff KM, Pedersen HC, Nielsen JV, Rasmussen TE, Fisker $M F$, Finsen B, Pedersen KM, Jensen NA: Characterization of two novel nuclear BTB/POZ domain zinc finger isoforms. Association with differentiation of hippocampal neurons, cerebellar granule cells, and macroglia. J Biol Chem 2002, 277:7598-7609.

27. Ren A, Zhang H, Xie Z, Ma X, Ji W, He DZ, Yuan W, Ding YQ, Zhang XH, Zhang WJ: Regulation of hippocampus-dependent memory by the zinc finger protein Zbtb20 in mature CA1 neurons. J Physiol 2012, 590:4917-4932.

28. Rosenthal EH, Tonchev AB, Stoykova A, Chowdhury K: Regulation of archicortical arealization by the transcription factor Zbtb20. Hippocampus 2012, 22:2144-2156.

29. Nielsen JV, Nielsen FH, Ismail R, Noraberg J, Jensen NA: Hippocampus-like corticoneurogenesis induced by two isoforms of the BTB-zinc finger gene Zbtb20 in mice. Development 2007, 134:1133-1140.

30. de Geus EJ, van't Ent D, Wolfensberger SP, Heutink P, Hoogendijk WJ, Boomsma DI, Veltman DJ: Intrapair differences in hippocampal volume in monozygotic twins discordant for the risk for anxiety and depression. Biol Psychiatry 2007, 61:1062-1071. 
31. Xie Z, Ma X, Ji W, Zhou G, Lu Y, Xiang Z, Wang YX, Zhang L, Hu Y, Ding $Y Q$, Zhang WJ: Zbtb20 is essential for the specification of CA1 field identity in the developing hippocampus. Proc Natl Acad Sci U S A 2010, 107:6510-6515.

32. Cole J, Toga AW, Hojatkashani C, Thompson P, Costafreda SG, Cleare AJ, Williams SC, Bullmore ET, Scott JL, Mitterschiffthaler MT, Walsh ND, Donaldson C, Mirza M, Marquand A, Nosarti C, McGuffin P, Fu CH: Subregional hippocampal deformations in major depressive disorder. $J$ Affect Disord 2010, 126:272-277.

33. Czeh $B$, Lucassen PJ: What causes the hippocampal volume decrease in depression? Are neurogenesis, glial changes and apoptosis implicated? Eur Arch Psychiatry Clin Neurosci 2007, 257:250-260.

34. Stockmeier CA, Mahajan GJ, Konick LC, Overholser JC, Jurjus GJ, Meltzer HY, Uylings HB, Friedman L, Rajkowska G: Cellular changes in the postmortem hippocampus in major depression. Biol Psychiatry 2004, 56:640-650.

35. Stockmeier CA, Rajkowska G: Cellular abnormalities in depression: evidence from postmortem brain tissue. Dialogues Clin Neurosci 2004, 6:185-197.

36. Kohli MA, Lucae $S$, Saemann PG, Schmidt MV, Demirkan A, Hek K, Czamara D, Alexander M, Salyakina D, Ripke S, Hoehn D, Specht M, Menke A, Hennings J, Heck A, Wolf $C$, Ising M, Schreiber I, Czisch M, Muller MB, Uhr M, Bettecken T, Becker A, Schramm J, Rietschel M, Maier W, Bradley B, Ressler KJ, Nothen MM, Cichon S, et al: The neuronal transporter gene SLC6A15 confers risk to major depression. Neuron 2011, 70:252-265

37. Langfelder P, Horvath S: WGCNA: an R package for weighted correlation network analysis. BMC Bioinformatics 2008, 9:559.

38. Bell JT, Loomis AK, Butcher LM, Gao F, Zhang B, Hyde CL, Sun J, Wu H, Ward K, Harris J, Scollen S, Davies MN, Schalkwyk LC, Mill J, MuTHER C, Williams FM, Li N, Deloukas P, Beck S, McMahon SB, Wang J, John SL, Spector TD: Differential methylation of the TRPA1 promoter in pain sensitivity. Nat Commun 2014, 5:2978.

39. Bell JT, Tsai PC, Yang TP, Pidsley R, Nisbet J, Glass D, Mangino M, Zhai G, Zhang F, Valdes A, Shin SY, Dempster EL, Murray RM, Grundberg E, Hedman AK, Nica A, Small KS, Dermitzakis ET, McCarthy MI, Mill J, Spector TD, Deloukas P: Epigenome-wide scans identify differentially methylated regions for age and age-related phenotypes in a healthy ageing population. PLoS Genet 2012, 8:e1002629.

40. Michels KB, Harris HR, Barault L: Birthweight, maternal weight trajectories and global DNA methylation of LINE-1 repetitive elements. PLOS One 2011, 6:e25254.

41. Gordon L, Joo JE, Powell JE, Ollikainen M, Novakovic B, Li X, Andronikos R, Cruickshank MN, Conneely KN, Smith AK, Alisch RS, Morley R, Visscher PM, Craig JM, Saffery R: Neonatal DNA methylation profile in human twins is specified by a complex interplay between intrauterine environmental and genetic factors, subject to tissue-specific influence. Genome Res 2012, 22:1395-1406

42. Kang HJ, Voleti B, Hajszan T, Rajkowska G, Stockmeier CA, Licznerski P, Lepack A, Majik MS, Jeong LS, Banasr M, Son H, Duman RS: Decreased expression of synapse-related genes and loss of synapses in major depressive disorder. Nat Med 2012, 18:1413-1417.

43. Hajszan T, Szigeti-Buck K, Sallam NL, Bober J, Parducz A, Maclusky NJ, Leranth C, Duman RS: Effects of estradiol on learned helplessness and associated remodeling of hippocampal spine synapses in female rats. Biol Psychiatry 2010, 67:168-174.

44. Hajszan T, Dow A, Warner-Schmidt JL, Szigeti-Buck K, Sallam NL, Parducz A, Leranth C, Duman RS: Remodeling of hippocampal spine synapses in the rat learned helplessness model of depression. Biol Psychiatry 2009, 65:392-400.

45. Kessler RC, Ustun TB: The World Mental Health (WMH) Survey Initiative Version of the World Health Organization (WHO) Composite International Diagnostic Interview (CIDI). Int J Methods Psychiatr Res 2004 13:93-121.

46. Trull TJ, Verges A, Wood PK, Jahng S, Sher KJ: The structure of Diagnostic and Statistical Manual of Mental Disorders (4th edition, text revision) personality disorder symptoms in a large national sample. Personal Disord 2012, 3:355-369.

47. Bucholz KK, Cadoret R, Cloninger CR, Dinwiddie SH, Hesselbrock VM, Nurnberger JI Jr, Reich T, Schmidt I, Schuckit MA: A new, semi-structured psychiatric interview for use in genetic linkage studies: a report on the reliability of the SSAGA. J Stud Alcohol 1994, 55:149-158.
48. Cottler LB, Robins LN, Grant BF, Blaine J, Towle LH, Wittchen HU, Sartorius N: The CIDI-core substance abuse and dependence questions: cross-cultural and nosological issues, The WHO/ADAMHA Field Trial. Br J Psychiatry 1991, 159:653-658.

49. Nasiri H, Forouzandeh M, Rasaee MJ, Rahbarizadeh F: Modified salting-out method: high-yield, high-quality genomic DNA extraction from whole blood using laundry detergent. J Clin Lab Anal 2005, 19:229-232.

50. Li H, Ruan J, Durbin R: Mapping short DNA sequencing reads and calling variants using mapping quality scores. Genome Res 2008, 18:1851-1858.

51. Patek RK, Jain M: NGS QC Toolkit: A Toolkit for Quality Control of Next Generation Sequencing Data. PLOS One 2012, 7:e30619.

52. Li H, Durbin R: Fast and accurate long-read alignment with Burrows-Wheeler transform. Bioinformatics 2010, 26:589-595.

53. Chavez L, Jozefczuk J, Grimm C, Dietrich J, Timmermann B, Lehrach $H$, Herwig R, Adjaye J: Computational analysis of genome-wide DNA methylation during the differentiation of human embryonic stem cells along the endodermal lineage. Genome Res 2010, 20:1441-1450.

54. Barrett T, Wilhite SE, Ledoux P, Evangelista C, Kim IF, Tomashevsky M, Marshall KA, Phillippy KH, Sherman PM, Holko M, Yefanov A, Lee H, Zhang N, Robertson CL, Serova N, Davis S, Soboleva A: NCBI GEO: archive for functional genomics data sets-update. Nucleic Acids Res 2013, 41:D991-D995.

55. Lindstrom MJ, Bates DM: Newton-Raphson and EM algorithms for linear mixed-effects models for repeated-measures data. J Am Stat Assoc 1988, 83:1014-1022.

56. Stepanow S, Reichwald K, Huse K, Gausmann U, Nebel A, Rosenstiel P, Wabitsch M, Fischer-Posovszky P, Platzer M: Allele-specific, age-dependent and BMI-associated DNA methylation of human MCHR1. PLoS One 2011, 6:e17711.

57. Thapar M, Covault J, Hesselbrock V, Bonkovsky HL: DNA methylation patterns in alcoholics and family controls. World J Gastrointest Oncol 2012, 4:138-144.

58. Selamat SA, Chung BS, Girard L, Zhang W, Zhang Y, Campan M, Siegmund KD, Koss MN, Hagen JA, Lam WL, Lam S, Gazdar AF, Laird-Offringa IA: Genome-scale analysis of DNA methylation in lung adenocarcinoma and integration with mRNA expression. Genome Res 2012, 22:1197-1211.

59. Gkrania-Klotsas E, Ye Z, Cooper AJ, Sharp SJ, Luben R, Biggs ML, Chen LK, Gokulakrishnan K, Hanefeld M, Ingelsson E, Lai WA, Lin SY, Lind L, Lohsoonthorn V, Mohan V, Muscari A, Nilsson G, Ohrvik J, Chao Qiang J, Jenny NS, Tamakoshi K, Temelkova-Kurktschiev T, Wang YY, Yajnik CS, Zoli M, Khaw KT, Forouhi NG, Wareham NJ, Langenberg C: Differential white blood cell count and type 2 diabetes: systematic review and meta-analysis of cross-sectional and prospective studies. PLOS One 2010, 5:e13405.

60. Adalsteinsson BT, Gudnason $H$, Aspelund T, Harris TB, Launer LJ, Eiriksdottir G, Smith AV, Gudnason V: Heterogeneity in white blood cells has potential to confound DNA methylation measurements. PLoS One 2012, 7:e46705.

61. Magi R, Morris AP: GWAMA: software for genome-wide association meta-analysis. BMC Bioinformatics 2010, 11:288.

62. Cochran WG: The comparison of percentages in matched samples. Biometrika 1950, 37:256-266.

63. Higgins JP, Thompson SG: Quantifying heterogeneity in a meta-analysis. Stat Med 2002, 21:1539-1558.

64. Trabzuni D, Ryten M, Walker R, Smith C, Imran S, Ramasamy A, Weale ME, Hardy J: Quality control parameters on a large dataset of regionally dissected human control brains for whole genome expression studies. J Neurochem 2011, 119:275-282.

65. Kadarmideen HN, Watson-Haigh NS: Building gene co-expression networks using transcriptomics data for systems biology investigations: Comparison of methods using microarray data. Bioinformation 2012, 8:855-861.

66. Battle A, Mostafavi S, Zhu X, Potash JB, Weissman MM, McCormick C, Haudenschild CD, Beckman KB, Shi J, Mei R, Urban AE, Montgomery SB, Levinson DF, Koller D: Characterizing the genetic basis of transcriptome diversity through RNA-sequencing of 922 individuals. Genome Res 2014, 24:14-24.

67. Mostafavi S, Battle A, Zhu X, Urban AE, Levinson D, Montgomery SB, Koller D: Normalizing RNA-sequencing data by modeling hidden covariates with prior knowledge. PLoS One 2013, 8:e68141. 
68. Trapnell C, Pachter L, Salzberg SL: TopHat: discovering splice junctions with RNA-Seq. Bioinformatics 2009, 25:1105-1111.

69. Chandramohan R, Wu PY, Phan JH, Wang MD: Benchmarking RNA-Seq quantification tools. Conf Proc IEEE Eng Med Biol Soc 2013, 2013:647-650.

70. Li H, Handsaker B, Wysoker A, Fennell T, Ruan J, Homer N, Marth G, Abecasis G, Durbin R: The Sequence Alignment/Map format and SAMtools. Bioinformatics 2009, 25:2078-2079.

71. Levinson DF: The genetics of depression: a review. Biol Psychiatry 2006, 60:84-92.

doi:10.1186/gb-2014-15-4-r56

Cite this article as: Davies et al:: Hypermethylation in the ZBTB20 gene is associated with major depressive disorder. Genome Biology 2014 15:R56.

\section{Submit your next manuscript to BioMed Central and take full advantage of:}

- Convenient online submission

- Thorough peer review

- No space constraints or color figure charges

- Immediate publication on acceptance

- Inclusion in PubMed, CAS, Scopus and Google Scholar

- Research which is freely available for redistribution 